\title{
Economic Geography, Trade, and War
}

\author{
DAVID H. BEARCE \\ Department of Political Science, University of Pittsburgh \\ ERIC O'N. FISHER \\ Department of Economics, The Ohio State University
}

\begin{abstract}
An agent-based model in which economic exchange and military conflict are emergent processes is used to explore the relationship between trade and war. The model of exchange is an applied analysis of the economics of trading networks. The model of conflict treats war as a breakdown in interstate bargaining due to incomplete information. The simulations explore how initial economic geography, state revisionism, defensive advantage, and technological advancement akin to globalization affect both trade and war. The results show that the relationship between trade and war depends on third factors, and an inverse relationship between trade and war emerges from compact geographies with revisionist states.
\end{abstract}

What is the relationship between international trade and war? Liberal scholars, such as Rosecrance (1986), Doyle (1986), Oneal et al. (1996), and Oneal and Russett (1997), generally posit an inverse relationship between international trade and war because trade links may create a disincentive to engage in military conflict. Realist scholars sometimes hypothesize a positive relationship; Liberman (1996) argues that military conquest remains a potentially efficient way to acquire resources, and Hoffman (1963) shows that increased economic interactions may actually sow the seeds of conflict by creating dependent economic relationships described by Waltz (1970). Others, such as Buzan (1984), argue that there should be no real correlation at all between trade and war because the origins of trade are different from the causes of war. ${ }^{1}$

In examining the empirical implications of this debate, scholars have employed a limited set of tools, often using statistical analyses that are not based on an underlying

1. Good recent surveys of this broad literature can be found in McMillan (1997) and Mansfield and Pollins (2001).

AUTHORS' NOTE: The authors are grateful for the comments of three anonymous referees, Kathryn Marshall, Todd Schoellman, Erik Gartzke, Jack Hirshleifer, Earl Thompson, David Hineline, and seminar participants at the 2000 Mershon Conference on Interdependence and Conflict, the UCLA Computational Social Sciences Colloquium in the winter of 2001, the Seventh International Conference of the Society for Computational Economics, and the Midwest International Economics Meetings in the fall of 2001. Fisher's research was supported by grants from the National Science Foundation and The Ohio State University's Mershon Center. All the Gauss programs and their output described in the simulations below are available at http://economics.sbs.ohio-state.edu/efisher/egtw. 
structural model. One problem with econometric inference is that the observed history of the world has actually run along only one particular path. Different trade networks and patterns of military conflict could well have emerged from seemingly random decisions and small changes in initial conditions - a key insight from the new wave of counterfactual analysis including Tetlock and Belkin's (1996) volume. Another problem is that such statistical models force one to treat either trade or war as an exogenous variable. This perspective may lose the insight that trade and war are both endogenous processes. Neither is outside the international system; indeed, each may be an emergent property within a system of states motivated to increase their resources and power.

Understanding that trade and war are both endogenous leads us to consider whether the relationship between economic exchange and military conflict may be governed by third factors. Two quick examples will help illustrate this point. Closer economic geography makes the growth of trading networks possible, but it can also render military conquest and the subsequent extraction of resources easier to achieve. Features of economic geography that facilitate trade, such as roads, bridges, and railways, can similarly be used for troop movements and resource extraction. Likewise, the impulse leading unitary states to invest in trade relationships with other states, namely the desire to acquire other states' resources—often called economic revisionism-is related to the motivation leading them to consider war. Revisionist states can improve their position within the international system through both war and trade, which, for example, may account for the distrust of some Western political leaders about China's entry into the World Trade Organization.

Scholars who model trade and war have long understood that external factors, such as economic geography, matter; it is now commonplace to include measures of distance in gravity models of trade and also to consider contiguity terms in models of interstate military conflict. Still, these terms function only as very crude approximations of economic geography. We agree with Gleditsch and Ward $(2000,6)$ who state, "The role of geography has been widely ignored." Our measure of economic geography accounts for both physical geography and economic infrastructure. Because of varying natural features, different regions in the international system have idiosyncratic economic geographies and disparately shaped trading networks. The economic geography in Western Europe is relatively compact compared with the distended geography in South America; this difference may help to account for the historically high levels of both trade and war within the former.

Revisionism can be defined as the desire of certain states in the international system to acquire additional power, which is usually measured in terms of material resources. Traditional realist scholars such as Morgenthau (1948) and Schweller (1994) often identify revisionism as an important source of military conflict. Scholarship on trade and war has neglected the role of revisionism in generating economic exchange; indeed, it is worth exploring in detail how a state's impulse to acquire resources can affect both war and trade. An important contribution of our work is that we offer an analytically cogent measure of state revisionism using a simple measure of the elasticity of substitution. The Armington aggregator common in empirical studies of international trade implies that a highly revisionist state has strong economies of scope. If 
such a state obtains a diverse resource base, it will achieve a large increase in military power.

We use an agent-based model that treats trade and war as emergent processes in a system of states. This model allows us in essence to "rerun history," examining the impact of random events and changes in initial conditions. Configured in different initial economic geographies, the states begin in autarky, and each is endowed with a unique tradable good. A state begins to trade with another state if it can pay the fixed cost of opening and maintaining commercial relations. A state may also demand resources from another state; as a result of these threats, costly wars may occur.

This model is novel in its treatment of both trade and war. Emphasizing that trade is not just a bilateral phenomenon, the model functions as an applied theoretical analysis of the economics of trading networks. One key feature is the trade-off between the fixed costs of setting up and maintaining trade links and the benefits of increased diversity in consumption. These fixed costs are endogenous; thus, in an important sense, the evolution of the economic geography is an emergent property of the opportunities for exchange. ${ }^{2}$ Trading networks arise spontaneously and have an ambiguous effect on the likelihood of conflict. For example, we show that a state will not go to war with another state that is fully integrated into its trading group, but it will fight with a near neighbor that is part of a complementary group. Indeed, the potential gains from conflict will be higher if the defending state has many different trading partners and thus a rich array of new goods available for usurpation.

Although there have been several notable agent-based computer models of war, ${ }^{3}$ our work also represents one of the first efforts to apply the insights of formal theorists such as Fearon (1995) and Morrow (1989), who argue that war tends to result from a breakdown of interstate bargaining due to incomplete information. In our model, when a state makes a demand for resources, it cannot know whether it faces a weak or strong defender. Weak defenders generally capitulate to all but the most extreme demands, but war will occur when a state demands resources from a committed defender who resists the threat. Wars thus occur randomly, as in Gartzke's (1999) model.

The remainder of the article is organized into four sections. The second section describes the model. The third investigates some of its analytical properties. The fourth section reports the simulation results that are the empirical heart of the model. The fifth section concludes.

\section{THE MODEL}

The world consists of $m$ states. Each state is endowed at time $t$ with an idiosyncratic $\operatorname{good} \omega_{i}(t)$, and the list of states is the index set $i \in M=\{1, \ldots, m\}$. A state's endowment

2. One can think of the current economic geography of the world system as an evolving state variable. The initial economic geography is clearly exogenous. A good survey of the recent theoretical developments in economic geography is that of Fujita, Krugman, and Venables (1999). Almost all this literature focuses on very simple, static, spatial environments.

3. Epstein and Axtell (1996), Cederman (1994), Cusack and Stoll (1990), and Bremer and Mihalka (1977) are examples. 
depends on time because a state that loses a war suffers a diminution of its economic resources. Also, because each state has its own good, there is a simple relationship between patterns of trade and the structure of demand in the world economy. We are using the analytical artifice of a state-specific composite commodity to capture the notion that every state has comparative advantage in some good.

Each state has preferences that are summarized by a utility function, $u_{i}: R_{+}^{m} \rightarrow R$, whose rule $u_{i}(x)$ also serves as the foundation for an expected utility indicator. For analytical simplicity, we assume that each state is risk neutral, and we impose further that

$$
u_{i}(x)=\left(\sum_{k=1}^{m} x_{k}^{\rho_{i}}\right)^{1 / \rho_{i}}, 0 \leq \rho_{i} \leq 1,
$$

where $x_{k}$ is the $k$ th component of the vector $x$. Thus, states have identical homothetic preferences, and each state values every good in the world economy.

The parameter $\rho_{i}$ merits some discussion. As $\rho_{i}$ tends toward zero, the $i$ th state becomes more desirous of others' goods. As $\rho_{i}$ tends toward unity, it becomes more content with its own good. We believe this measure offers a useful way to capture the concept of "revisionism," ${ }^{4}$ with larger $\rho_{i}$ values indicating less revisionism. International relations theorists such as Morgenthau (1948), Kissinger (1957), and Carr (1946) identify revisionist states as those dissatisfied with the status quo, a limited basket of goods in a model of economic exchange. Schweller and Preiss $(1997,11)$ emphasize that such states are often desirous of greater power, which is usually measured in terms of material resources. Thus, our measure captures aspects of both unitlevel satisfaction and power.

Equation (1) can also be interpreted as an Armington aggregator for an economy's productive capacity. Using this interpretation, one can consider the equation as a production function, aggregating a potentially diverse resource base into a homogeneous final good called national output. If $\rho_{i}$ is small, then an economy has strong economies of scope and benefits greatly from a diverse resource base. Thus, when a revisionist state obtains a diverse basket of goods, it will become substantially more powerful in military terms.

\section{ECONOMIC EXCHANGE ${ }^{5}$}

A trading network is a collection of sets $\left\{S_{i}\right\}_{i=1}^{m}$ that cover $M$. Each $S_{i}$ is the list of trading partners of the $i$ th state. Because this collection covers the index set of states, $M \subseteq \bigcup_{i=1}^{m} S_{i}$. This collection of sets must satisfy two consistency properties. First, $i \in S_{i}$ because every state is its own trading partner. Second, if $j \in S_{i}$, then it must be the case

4. Economists identify $\rho_{i}$ as an elasticity parameter. When $\rho_{i}$ is near unity, goods are almost perfect substitutes, and the desire for variety is attenuated.

5. The model of economic exchange draws heavily on the excellent work of Jodhimani (1999). 
that $i \in S_{j}$. For example, if $\left\{S_{i}\right\}_{i=1}^{m}=\{\{1\}, \ldots,\{m\}\}$, then all the states in the world are in autarky, or if $\left\{S_{i}\right\}_{i=1}^{m}=\{M, \ldots, M\}$, then the world economy is completely integrated.

Trading with another state requires paying fixed costs that depend on the current (and thus time-dependent) economic distance between trading partners. Consider a symmetric $m \times m$ matrix,

$$
A(t)=\left[\begin{array}{cccc}
0 & \cdots & a_{1 j}(t) & \cdots \\
\vdots & \ddots & & a_{i m}(t) \\
a_{j 1}(t) & & \ddots & \vdots \\
\vdots & \cdots & a_{m j}(t) & 0
\end{array}\right],
$$

whose canonical element $0 \leq a_{i j}(t)$ measures the economic distance between states $i$ and $j$ at time $t$. This matrix has two simple properties. First, the distance from a state to itself is zero. Second, the distance from $i$ to $j$ is the same as the distance from $j$ to $i{ }^{6}$

We follow the tradition in the literatures on international trade and economic geography, imposing that economic distance is the fraction of resources that a state pays to maintain its commercial relations with any trading partner. It is useful to define a trade indicator function:

$$
\chi_{i j}(t)=\left\{\begin{array}{l}
1 \text { if } j \in S_{i} \\
0 \text { otherwise. }
\end{array}\right.
$$

This function simply tracks who is trading with whom; it takes the value of unity if states $i$ and $j$ are trading partners and zero otherwise.

Now let the initial economic geography $A(0)$ be given. We assume that economic distance evolves according to

$$
a_{i j}(t+1)=a_{i j}(t) \exp \left(-\delta \chi_{i j}(t)-\theta\right)
$$

where $\delta$ is the parameter that captures the rate at which trading costs decrease if a trading link between state $i$ and state $j$ is extant. The parameter $\theta$ is the exogenous rate at which the economic geography becomes more compact in every period. Thus, the economic distance between two states shrinks as long as the trading links between them have not been severed, and it may also shrink if there is exogenous technological progress that makes trade between all countries easier. Also, in the spirit of the strong symmetry of the model, this learning-by-trading parameter $\delta$ applies to every link equally.

6. We do not impose the triangle inequality a priori in this matrix because these numbers describe economic distance, not spatial geography. For example, it is entirely plausible that the economic distance between Cuba and the United States is greater than the sum of the economic distances from Cuba to Mexico and then from Mexico to the United States. 
Let $a_{i}(t)=\sum_{j=1}^{m} \chi_{i j}(t) a_{i j}(t)$. Then the real cost that state $i$ pays to maintain its trading links is described by $\exp \left[-a_{i}(t)\right]$. Because this fixed cost is a fraction of state $i$ 's endowment, its net endowment available for trade is $\widetilde{\omega}_{i}(t)=\exp \left[-a_{i}(t)\right] \omega_{i}(t)$. The most important aspect of this formulation is that bilateral trade costs become lower if countries establish a link, and they do not return to higher levels if that link is temporarily abandoned.

The economic equilibrium in the world economy is a "price vector," $p=\left(p_{1}, \ldots, p_{m}\right)$, and corresponding list of allocations, $x=\left\{x_{i}\right\}_{i=1}^{m}$ such that each state maximizes utility, taking its own terms of trade, the current economic geography, and the trading structure as given. Also, the obvious materials balances condition holds; thus, demand for any one good does not exceed its supply. The phrase "price vector" is in quotes because it is not necessarily true that every state trades for every good. These numbers do not describe the marginal rates of substitution between pairs of commodities for representative agents in the world economy. Instead, they are more akin to state-specific terms of trade. Recall that $S_{i}$ is the list of trading partners for the $i$ th state; its terms of trade are the vector $\tilde{p}_{i}=\left(p_{j} / p_{i}\right)_{j \in S_{i}}{ }^{7}$

It is convenient to write $y_{i}(t)=p_{i} \tilde{\omega}_{i}(t)$. Then the demand of the $i$ th state for the $j$ th good is

$$
x_{i j}(t)=\left\{\begin{array}{c}
y_{i}(t) p_{j}^{r_{i}-1} / \sum_{j \in S_{i}} p_{j}^{r_{i}} \text { if } j \in S_{i} \\
0 \text { otherwise }
\end{array},\right.
$$

where $r_{i}=\rho_{i} /\left(\rho_{i}-1\right){ }^{8}$ Thus, only a state's terms of trade matter in describing its pattern of demand, and the usual materials balances condition can be written as $\sum_{i=1}^{m} x_{i}-\sum_{i=1}^{m} \widetilde{\omega}_{i}$ $\leq 0 \in R^{m}$. In other words, at the current terms of trade, the demand for each country's resources does not exceed its supply, even after the fixed costs of maintaining the trading network have been paid.

\section{CONFLICT AND MILITARY CONQUEST}

The economic equilibrium is only half the picture. The second part of the model consists of an explicit description of conflict and possible war. ${ }^{9}$ The essence of this process is captured by a simple parable. Consider a bully trying to extort your lunch money. The bully can observe many relevant characteristics: your height, your weight, and your degree of fitness, among other things. But he cannot observe your resolve for

7. Calculating these terms of trade for an arbitrary description of the trading network is the most timeconsuming part of the computer simulations. We used a fixed-point algorithm extending Judd $(1998,188)$.

8. If we think of equation (1) as an Armington aggregator, then these are the derived demands for intermediate inputs necessary to produce a homogeneous final good called national output.

9. There are many different theories explaining the outbreak of war, and the idea behind this model is as old as the Melian dialog of Thucydides. We are very grateful to a referee who suggested that we develop a model of war as a breakdown in interstate bargaining owing to private or incomplete information. 
self-defense. The bully is rational, recognizing that an actual fight will entail costs for both parties. So he tries to decide just how far to push. The bully has prior beliefs about how spunky you are, and if he thinks there is a high likelihood that you are tough, then he will extort little or nothing. Both weak and strong defenders will acquiesce if the demand is not very onerous to avoid the costs of actual physical conflict. But if the bully thinks there is little likelihood that you are tough, then he will ask for more money, just enough so that weak types-perhaps a large majority of the populationwill not be willing to fight. In this case, he will get a decent amount of money most of the time, but every now and again, he will have to fight a spunky defender. In those situations, he will often lose the fight. The rest of this subsection will make this model explicit.

Consider an extant trading network with corresponding equilibrium allocations $x=\left\{x_{i}\right\}_{i=1}^{m}$. Each state's economic power is given by its gross national product $u_{i}\left(x_{i}\right)$. A rich group of trading partners bolsters the economic and thus the military power of a state. ${ }^{10}$ It also gives revisionism analytical bite because a state with a low $\rho_{i}$ will have disproportionate military power if it manages to secure a diverse pattern of trade.

Write $u_{i}=u_{i}\left(x_{i}\right)$ and $u_{j}=u_{j}\left(x_{j}\right)$, and consider a simple function:

$$
w\left(u_{i}, u_{j}\right)=\frac{u_{i}}{u_{i}+\widetilde{\Phi} u_{j}},
$$

where $\widetilde{\Phi}$ is a (systemic) random defense parameter. ${ }^{11}$ This random variable is how we introduce different types of defenders into this model. Given a realization of $\widetilde{\Phi}$, this function describes the probability that an attack by state $i$ against state $j$ will succeed. It is customary to model different types of belligerents by assuming that states have different costs of going to war. Instead, we model different types by the effectiveness of their defensive capabilities. An attacker has to be concerned about meeting a tough defender, so we can think about a high realization of $\widetilde{\Phi}$ as a low cost of defense. The actual realization of this random variable is not observable, so any potential attacker has to make an ex ante decision based on the known distribution of the costs of defense.

Each state's gross national product enters equation (3) in a natural way. In particular, an economically large state attacking a smaller one has a high probability of winning a war. Of course, each of the arguments in this function depends on time. Thus, the probability of war may depend on the evolution of economic distance and the value of a state's consumption pattern, determined according to its current terms of trade. It also depends on whether the defending state is strong and thus has a large realization of $\widetilde{\Phi}$. We assume that $\widetilde{\Phi}$ is a binomial (and thus the simplest possible) random variable, and we write $1 \leq \varphi_{0}<\varphi_{1}$ as the two elements of its support. Even a weak defender does not have a disadvantage, and a strong defender can have a substantial defensive advantage.

10. This specification underlies realist arguments about "relative gains" and the potential pitfalls of engaging in international trade. See Grieco $(1988,1990)$, and Mastanduno (1991).

11. The analytical form in equation (3) is a special case of the contest success function described by Hirshleifer (1995). 
The decision to go to war is made unilaterally by the attacking state $i$. This assumption stands in sharp contrast with the decision to alter a trading link, which depends on a bilateral Pareto improvement for the two states concerned. If war does occur, it has a random outcome. If the attacker wins, then it achieves utility

$$
u_{i}\left[\exp \left(-a_{i j}(t)\right)\left(x_{i}+(1-\sigma) x_{j}\right)\right],
$$

where $0<\sigma<1$ is a (systemic) parameter that captures the subsistence level for each state. Three comments are in order. First, the cost of going to war is that the attacker must pay a fraction $1-\exp \left(-a_{i j}(t)\right)$ of its resources, including its potential booty. Second, although economic geography does not enter explicitly into the technology of war as summarized by the attack function, it does enter into the calculation of the spoils of war. In particular, if two states are far apart, then it costs the attacker a lot to wage war. Also, the attacker reaps relatively small benefits from usurping the losing defender's net trades. Third, the benefits from winning an attack are myopic; they are a one-time gain that depends on the richness of the defender's trading pattern. If the attacker loses, then it has utility $u_{i}\left[\exp \left(-a_{i j}(t)\right) \sigma x_{i}\right]$; it uses up all but a subsistence level of its remaining resources in a futile attack. Also, we impose that the losing attacker has a permanently lower endowment $\sigma \omega_{i}$.

If the defender loses, it achieves utility $u_{i}\left(\sigma x_{j}\right)$, and its endowment remains permanently lower at $\sigma \omega_{i}$. On the other hand, if the defender wins, then its utility remains unchanged at $u_{j}\left(x_{j}\right)$, and its endowment is also unchanged. Any country-attacker or defender - that loses a war will have an endowment at a subsistence level, and such an endowment precludes the possibility that it will be an attacker in the future. Thus, war is a permanently destructive activity for the world economy.

Knowing the nature of war, the attacking state makes a threat, called euphemistically a demand for additional resources. Let $\pi(\varphi)=\frac{u_{i}}{u_{i}+\varphi u_{j}}$ be the probability that an attacker wins against a defender of type $\varphi$; we have suppressed the other arguments, all of which are publicly observable economic variables, for notational convenience. Notice that a risk-neutral defender of type $\varphi$ will acquiesce in a demand not greater than $\pi(\varphi)(1-\sigma) x_{j}$, the expected loss from fighting a war. Thus, a defender will give up a large fraction of its resources if it is not likely to win or if war is Draconian. Also, tough defenders give up less, because $\pi\left(\varphi_{1}\right)<\pi\left(\varphi_{0}\right)$ and the odds of beating a tough defender are smaller.

Now what is the optimal threat for an attacker to make? What is the largest resource concession that an attacker will demand? If the attacker actually goes to war against a defender of type $\varphi$, it will receive expected utility

$$
v_{i}(\varphi)=\pi(\varphi) u_{i}\left[\exp \left(-a_{i j}(t)\right)\left(x_{i}+(1-\sigma) x_{j}\right)\right]+[1-\pi(\varphi)] u_{i}\left[\exp \left(-a_{i j}(t) \sigma x_{i}\right)\right] .
$$

There are three possibilities. First, an attacker will never actually go to war if it demands only $\pi\left(\varphi_{1}\right)(1-\sigma) x_{j}$; think of this threat as asking for a nickel-and-dime concession. Second, it will end up going to war against only tough defenders if it demands 
$\pi\left(\varphi_{0}\right)(1-\sigma) x_{j}$, representing a more hefty concession. Third, it will surely go to war if it demands any more than that.

Let $0 \leq c_{j} \leq 1$ be the demand for current resources that the attacker puts on the table; it is convenient to express this demand as a fraction of the defender's allocation $x_{j}$. Assume also that a proportion $0<\mu<1$ of the defenders are weak. Then the attacker's expected utility is

$$
z_{i}\left(c_{j}\right)=\left\{\begin{array}{cc}
u_{i}\left(x_{i}\right) & \text { if } c_{j} /(1-\sigma)=0 \\
u_{i}\left(\exp \left(-a_{i j}(t)\right)\left(x_{i}+c_{j} x_{j}\right)\right) & \text { if } 0<c_{j} /(1-\sigma) \leq \pi\left(\varphi_{1}\right) \\
\mu u_{i}\left(\exp \left(-a_{i j}(t)\right)\left(x_{i}+c_{j} x_{j}\right)\right)+(1-\mu) v_{i}\left(\varphi_{1}\right) & \text { if } \pi\left(\varphi_{1}\right)<c_{j} /\left(1-\sigma_{j}\right) \leq \pi\left(\varphi_{0}\right) \\
\mu v_{i}\left(\varphi_{0}\right)+(1-\mu) v_{i}\left(\varphi_{1}\right) & \text { otherwise. }
\end{array}\right.
$$

The first branch of equation (4) corresponds to making no demands and maintaining the status quo ex ante. The second branch is the sure utility of making only a nickeland-dime demand. The third branch is the expected utility of making a large enough demand so that one might have to fight a strong defender. And the fourth branch is the expected utility of going to war for sure. The argument that maximizes (4) is the optimal demand. A war occurs only if the attacker demands a large concession and meets a tough defender by chance.

How does a demand for resources (namely, a threat $c_{j}>0$ ) and the possible outbreak of war affect the trading network? In the event of any threat at time $t$, we impose that $\chi_{i j}(t+1)=0$ and $\chi_{j i}(t+1)=0$. If war does break out, then either the attacker or the defender loses. Hence, one of these two states will have a subsistence endowment permanently. Having such an endowment makes it impossible ever to be an attacker again, and it often precludes any future trade. Indeed, the only way that such a state can afford to pay the fixed cost of maintaining its trading links is if the economic geography has already evolved so that the economic distance to its nearest neighbor is sufficiently small.

This description of threats and the outcome of war assumes that third parties in the world economy are neutral, an assumption that could be relaxed in a more complex model. In particular, in any period when there is a war, both states $i$ and $j$ consider their trades with third parties as given. Still, third parties will be affected deleteriously in the next period in the case of war because the aggregate resources in the world economy become lower, no matter who wins. This specification of war's outcome is Draconian, but it has the virtue of analytical simplicity. It is also consistent with Liberman's (1996) finding that only the most ruthless conquerors can extract a large net economic surplus from the states they vanquish.

\section{TIMING OF DECISIONS}

The world economy starts out initially in autarky and a state of peace. The economic geography and the initial distribution of resources are taken as given. In each period, two states are chosen randomly, and the pair considers changing the current 
trading network. They can create a new trading link or sever one if they are currently trading partners. If, after paying the fixed cost of creating the new link, the two states experience a strict Pareto improvement, then the new network becomes a possibility for next period's status quo. Or, if after saving the fixed costs of the current link and foregoing the increased diversity in consumption that it entails, both states are strictly better off, then a new (less expansive) trading network becomes the possible future status quo. Otherwise, the current network remains unchanged. Both these decisions are myopic and ignore the effects that they have on third parties. But they are based on the equilibrium terms of trade that occur if the new link is established or if an old one is severed.

Let $\Xi(t)$ be the symmetric $m \times m$ matrix whose canonical element is $\chi_{i j}(t)$; the initial trading pattern is given by $\Xi(0)=I$. Let the current equilibrium allocations be $\left\{x_{i}\right\}_{i=1}^{m}$ and those that would occur if the trading pattern were changed be $\left\{\tilde{x}_{i}\right\}_{i=1}^{m}$. Recall that both these allocations depend on the disparate prices and concomitant fixed costs in the two different trading networks. Furthermore, keep the definition of $z_{i}\left(c_{j}\right)$ in equation (4) in mind. Then the evolution of the trading pattern for $t \geq 0$ can be stated formally as ${ }^{12}$

$$
\chi_{i j}(t+1)=\left\{\begin{array}{cc}
1-\chi_{i j}(t) & \text { if } u_{i}\left(\tilde{x}_{i}\right)>u_{i}\left(x_{i}\right), u_{j}\left(\tilde{x}_{j}\right)>u_{j}\left(x_{j}\right) \text {, and } \max z_{i}\left(c_{j}\right) \leq u_{i}\left(\tilde{x}_{i}\right) \\
\chi_{i j}(t) & \text { if } u_{i}\left(\tilde{x}_{i}\right) \leq u_{i}\left(x_{i}\right) \text { or } u_{j}\left(\tilde{x}_{j}\right) \leq u_{j}\left(x_{j}\right) \text { and } \max z_{i}\left(c_{j}\right) \leq u_{i}\left(x_{i}\right) \\
0 & \text { otherwise. }
\end{array}\right.
$$

Because the argument that maximizes (4) takes into account the possibility of fighting, the attacker will only make a demand for a resource concession and risk going to war if it is not satisfied with the outcome of the current trading network. Equation (5) describes a Markov process defined on the state space consisting of the bilateral trade links between all states, including the trivial link between a state and itself. Thus, the evolution of the world trading system is summarized by the random sequence $\{\Xi(t)\}_{t=0}^{\infty}$. The simulations described in the next section are essentially an empirical investigation of the behavior of this sequence.

Thus, the initial economic distances between states and the random process of trade and conflict give rise to a dynamical system. The steady state (or cyclical behavior) of this system describes the long-run trading network. If the initial economic distance between states is large enough and the states' endowments are roughly symmetric, then the unique long-run outcome will be autarky. War against a distant neighbor is too costly, and it is also too difficult to set up mutually beneficial trades. On the other hand, if some pair of states is sufficiently close, then both war and trade become feasible. Also, asymmetric gains from trade — reflected in the terms of trade—or an asymmetric distribution of resources may make some states temporarily powerful. This imbalance of power will have random effects on the outbreak of war and the subsequent distribution of resources in the world economy.

12. Please remember that $\chi_{j i}(t)=\chi_{i j}(t)$, too. 


\section{ANALYTICAL ASPECTS OF THE MODEL}

Consider a state with net endowment $\widetilde{\omega}_{i}(t)$ and trading partners $S_{i}$. If its terms of trade are $\tilde{p}_{i}$, then its indirect utility is $V_{i}\left(\tilde{p}_{i}, y_{i}(t)\right)=\tilde{\omega}_{i}(t) /\left(\sum_{i \in S_{i}} \tilde{p}_{i}^{r_{i}}\right)^{1 / r_{i}}$. Here we have used the fact that a state's income is $y_{i}(t)=p_{i} \tilde{\omega}_{i}(t)$. A state's welfare is directly related to its endowment after paying the fixed cost for its trading network. Also, an increase in $\widetilde{p}_{j}$ for $j \in\left(S_{i}-\{i\}\right)$ will decrease a state's well-being; thus, a worsening in the terms of trade has the expected negative effect. Using the materials balances condition, one can show that an increase in a state's net endowment worsens its terms of trade. Finally, it is easy to check that such an increase raises a state's welfare, in spite of the terms-of-trade effect.

Revisionism plays an important role. In particular, a state with a high degree of revisionism (a relatively low value of $\rho_{i}$ ) will become militarily powerful if it achieves a diverse resource base. Consider two states forming an isolated trading group, one with $\rho_{i}=.2$ and the other with $\rho_{j}=.4$. If their endowments satisfy $\omega_{i}=\omega_{j}=2$ and the economic distance between them is $a_{i j}(t)=0$, then they will find economic exchange mutually beneficial. The equilibrium allocations will be $x_{i}=x_{j}=(1,1)^{\prime}$. But then the gross national product (measured as the utility level) of the revisionist state will be $32=\left(1^{2}+\right.$ $\left.1^{2}\right)^{5}$, whereas that of its trading partner will be $4 \sqrt{2}=\left(1^{4}+1^{4}\right)^{2.5}$, a much smaller number. In autarky, each state had a gross national product of 2 , but trade and the concomitant access to a diverse resource base make the revisionist state much richer and thus stronger militarily.

Let $\underline{a}_{i}(t)=\min _{j} a_{i j}(t)$ and $\bar{a}_{i}(t)=\max _{j} a_{i j}(t)$ be the economic distances to the nearest state and the farthest state respectively from state $i$ at time $t$. These are two important determinants of trade relations or military conflict. First, notice that if $\underline{a}_{i}(t)$ is sufficiently large, then state $i$ will neither trade nor enter into conflict with any other state. It will not trade because the increased diversity in consumption is not worth the large cost of setting up bilateral economic relations. And it will not go to war because equation (4) shows that the expected utility of attacking will never be as large as the utility of autarky, no matter how rich the defending state's trading pattern might be. Thus, the model is only interesting if the economic distance becomes sufficiently small such that at least one state is willing to trade with another. Second, if $\bar{a}_{i}(t)$ is sufficiently small, then state $i$ will be willing to trade with every other state, because the fixed cost of setting up bilateral exchange is small for every partner. Also, equation (4) shows that state $i$ may go to war, especially if it can attack a relatively weak state that has an attractive array of current resources.

What determines whether a state trades or goes to war in this model? It is worth examining equation (4) in detail to answer this question. First consider two states that are equal in every way. Thus, $\rho_{i}=\rho_{j}$ and $x_{i}=x_{j}$, and these two states have the same trading partners, the same sized net endowments, and face the same terms of trade. To make things very simple, assume that transportation costs are negligible and that war is very Draconian $(\sigma=0)$. 
If $1<\varphi_{0}=\varphi_{1} \equiv \varphi$, the defender's type is known with certainty. Going to war against an equally sized neighbor with a defensive advantage is a losing proposition. On the other hand, the optimal threat is $c_{j}=1 /(1+\varphi)$. The defender will acquiesce, and there will be a concession that depends naturally on how tough the defender is. There will never be war, but there will never be mutually beneficial trade either. Thus, the model predicts (random) cycles of resource concessions between equal states in a dyad when the economic distance between them is negligible and there are no gains from trade. On the other hand, if $a_{i j}(t)>0$ and the (known) defender is sufficiently tough, then there will never be any threats. Again, war does not pay for the attacker, and the optimal threat is still $c_{j}=1 /(1+\varphi)$. But the attacker's utility of making this threat is $u_{i}$ [exp $\left.\left(-a_{i j}(t)\right)\left(x_{i}+c_{j} x_{j}\right)\right]$, whereas that of maintaining the status quo is $u_{i}\left(x_{i}\right)$. Because $x_{i}=x_{j}$, we may conclude that the former is less than the latter if $(2+\varphi) /(1+\varphi)<\exp \left(a_{i j}(t)\right)$. In other words, if the cost of making a threat is just too great, then the dyad maintains the status quo and there will be no war. Indeed, the trade link between the two will be updated, and they will become closer in an economic geographic sense.

\section{ANALYTICAL DETERMINANTS OF CONFLICT}

When is war likely? Consider again two identical states located right next to one another and assume that $\rho_{i}=\rho_{j}, x_{i}=x_{j}, \sigma=0$, and $a_{i j}(t)=0$. Now also assume that with probability $\varepsilon>0$, the defender is very tough (namely, $\varphi_{1}$ is unboundedly large); and with probability $1-\varepsilon$, the defender is weak (and thus $\varphi_{0} \geq 1$ has moderate value). Speaking roughly, we can say that the expected utility of going to war against the tough type of defender is zero, because the attacker will lose almost surely. But making a nickel-and-dime threat is not very attractive, because the probability of actually meeting a tough defender is arbitrarily small. In this case, the optimal threat is $c_{j}=1 /\left(1+\varphi_{0}\right)$ $>1 /\left(1+\varphi_{1}\right) \approx 0$, and wars will occur with probability $\varepsilon>0$. If $\varepsilon$ is near 0 , then, using the same line of reasoning as above, we see that $(1-\varepsilon)\left(2+\varphi_{0}\right) /\left(1+\varphi_{0}\right)>\exp \left[a_{i j}(t)\right]=1$. Thus, the attacker will find it worthwhile to ask for large resource concessions as long as there is only a very small chance of meeting a tough defender. But when war does occur, the attacker will almost surely lose. Indeed, it is natural to assume that the weakest type of defender has $\varphi_{0} \approx 1$. Then $\left(2+\varphi_{0}\right) /\left(1+\varphi_{0}\right) \approx 3 / 2$; so war between equally powerful and geographically proximate states can break out about $1 / 3$ of the time if $2 / 3$ of the defenders are of the weakest type.

In fact, we can achieve an even deeper insight. Consider two states that have the same set of trading partners and, thus, $S_{i}=S_{j}$. In this case, the two states consume the same set of goods and, in particular, they are already trading partners. Because preferences are homothetic, they face the same terms of trade. Thus, their war weights are identical to the relative sizes of their gross national products, which depend upon the difference in their revisionism parameters. Assume now that the costs of war are slight. Then there are three possibilities: (1) the attacker has an overwhelming advantage against all type of defenders, (2) the attacker has an advantage against weak defenders but not against strong ones, or (3) there is (at most) rough parity between the attacker and all types of defenders. 
If the attacker has an overwhelming advantage against all types, it will demand large concessions and get them. If the attacker has an advantage only against weak defenders, it will still demand large concessions, as long as the share of strong defenders is small enough. In this case, wars will break out sporadically, and the attacker will often lose such conflicts. (If the share of strong defenders is large enough, then the attacker will make only nickel-and-dime threats and peace will prevail. The small fraction of weak defenders will be free riders.) If there is rough parity between the attacker and both types of defenders, then a state will make only nickel-and-dime threats. Indeed, even a weak attacker will make these small resource demands, because fighting is more costly even for the tough defender than paying nickel-and-dime concessions.

The common intuition behind these results is that the expected gain from resource concessions and possible war is not very large if both parties are already consuming the same bundle of goods. Also, war will occur only when the attacker demands a large trade concession and meets by chance a tough defender. This event will happen only when there are few tough defenders. This serves as an important insight: military conflict emerges in this model among states that do not have the same trading partners or if the share of weak defenders is sufficiently high. So we may conclude that states that are treated identically in the world trading system will not attack one another under normal circumstances, although they may well demand unilateral resource concessions if the cost of doing so is cheap. War will be avoided, but mutually beneficial trades will not occur.

\section{ANALYTICAL DETERMINANTS OF TRADE}

When is trade likely? First, the gains from trade must be high. The simplest case occurs when two states are in autarky and considering setting up bilateral trade. To make matters simple, assume that $\rho_{i}=\rho_{j} \equiv \rho$ and that each state is endowed with two units of its idiosyncratic good. Then $u_{i}=u_{j}=2$ and the two states are equally powerful. Because the two states have equal endowments and preferences are homothetic, then the terms of trade will be one to one. After having sunk the fixed costs for setting up the link, each state will have utility $2^{1 / \rho} \exp \left(-a_{i j}(t)\right)$, which is greater than autarkic utility as long as $a_{i j}(t)$ is not too large. Because $1 \leq \varphi_{0} \leq \varphi_{1}$ and the subsistence parameter $\sigma \geq 0$, the optimal demand for a resource concession is such that $c_{j} \leq 1 /\left(1+\varphi_{0}\right) \leq 1 / 2$. Furthermore, the expected utility of this concession can be no higher than $\left(2^{\rho}+\left(c_{j} 2\right)^{\rho}\right)^{1 / \rho}$ $\exp \left(-a_{i j}(t)\right)$ because the attacker might fight and lose. Thus, the attacking country will prefer trade as long as $2>2^{\rho}+2^{\rho-1}$, which is true for $\rho<.61$. These are two fairly weak sufficient conditions for symmetric counties to prefer trade to war: economic geographic proximity and a defensive advantage that is high relative to the attacker's degree of revisionism.

These observations have important implications for the long-run behavior of the world system. The model describes a Markov chain defined on the matrix of trading links $\Xi(t)$. Thus, the state space of the model is the set of symmetric $m \times m$ matrices whose canonical element is zero or unity; the initial state of the system is the $m \times m$ identity matrix. The long-run behavior of the world trading system is essentially sum- 
TABLE 1

Baseline Parameter Values

\begin{tabular}{ll}
\hline \hline Number of states & $m=6$ \\
Revisionism & $\rho_{i}=1 / 3 . i=1, \ldots, 6$ \\
Initial endowments & $\omega_{i}(0)=1, i=1, \ldots, 6$ \\
Subsistence level & $\sigma=.4$ \\
Share of weak defenders & $1-\mu=.72$ \\
Defensive advantage of a weak state & $\varphi_{0}=1$ \\
Defensive advantage of a strong state & $\varphi_{1}=8.14$ \\
Rate of learning by trading & $\delta=.04$ \\
Rate of exogenous technological progress affecting & \\
economic geography & $\theta=0$ \\
Share of resources needed to open trade with the nearest neighbor & $\underline{a}_{i}(0) / \omega_{i}(0)=0.5, i=1, \ldots, 6$ \\
\hline
\end{tabular}

marized by the absorbing states of the random process of trade or war. Because a state that loses a war reverts to subsistence level, it can never attack another state in the future. Also, for realistic subsistence levels, it may likely revert to autarky and stay there unless there is exogenous technological progress in the economic geographic infrastructure.

We have already seen that perpetual autarky is an absorbing state if the initial economic geography is sufficiently disjointed so that neither war nor trade can occur. ${ }^{13}$ Likewise, a perpetual random cycle of unilateral demands for small concessions can occur in a completely integrated world economy where every state is treated symmetrically, although it may not be possible to reach this condition from an initial state of autarkic economies. Because the model is highly nonlinear, it is difficult to derive analytical properties about its long-run behavior. Thus, one can perhaps best understand its long-run behavior by repeated simulations for different parameter values.

\section{SIMULATION RESULTS}

We begin by calibrating the model and specifying different initial economic geographic configurations for states in the system. We then use repeated replications of the model and report the results in four subsections below. The first subsection describes the effect of initial economic geography, the second shows how revisionism matters, the third looks at the defensive advantage in war, and the fourth examines the effect of exogenous technological progress affecting the economic geographic infrastructure.

The baseline parameters are given in Table 1. Our value for revisionism comes from Backus, Kehoe, and Kydland (1994), who report that most empirical models of international trade use an elasticity of substitution $1 \leq 1 /(1-\rho) \leq 2$ for the Armington aggregator. We chose the midpoint of this range as our starting value, giving all states

13. Indeed, this insight can be generalized; any country that is permanently sufficiently distant from all its neighbors will never become a part of the world's trading system; nor will it ever be involved in war. 
symmetrically $\rho=1 / 3$. The initial endowments were made completely symmetric and as simple as possible; it is worth emphasizing that utility is homogeneous of degree one in endowments. Thus, doubling a state's resources doubles its gross domestic product at a fixed terms of trade. We employed a simple calculation for the subsistence level $\sigma=.4$; using data from Maddison (1982), we estimated that German, Austrian, Italian, and Japanese production dropped, on average, around $60 \%$ from a wartime peak to a postwar trough immediately after World War II.

What is the proportion of weak defenders? Numerous scholars, such as Lake (1992), Reiter and Stam (1998), and Bueno de Mesquita et al. (1999), have demonstrated that democracies win a disproportionate share of wars, suggesting that they are relatively strong. ${ }^{14}$ The proportion of nondemocratic states in the international system between 1800 and 1994 was roughly $72 \%$, according to the Polity III data set of Jaggers and Gurr (1995). ${ }^{15}$ Thus, we set $1-\mu=.72$. The model has two other defense parameters: the defensive advantage in war for weak and for strong states. The average defensive advantage in war is commonly taken to be three (Mearsheimer 1989). It is plausible to assume that weak states have no defensive advantage and thus that $\varphi_{0}=1$. The defensive advantage of a strong state can then be identified as $\varphi_{1}=8.14$.

We select the learning-by-trading parameter using data from Maddison (1982), who calculates that the total value of world exports grew at an annual rate of $3.16 \%$ between 1870 and 1970, a century marked by military conflict. One interpretation is that average trading partners became about $3 \%$ closer each year after accounting for trade disruptions due to war. Because our model allows states to become closer only when they are at peace, we adjust the learning-by-trading parameter up to $\delta=.04$. Because we wish to focus on the endogenous evolution of trading networks, we begin by setting the rate of exogenous technological progress affecting economic geographic infrastructure $\theta=0$ for the base runs. Thus, states cannot become closer unless they engage in trade. Finally, we set the share of initial resources required to open trade with one's nearest neighbor as $\underline{a}_{i}(0) / \omega_{i}=0.5$; Wallis and North (1986) estimate that $50 \%$ of the American economy is devoted to transaction costs. Thus, the ratio $\underline{a}_{i}(0) / \omega_{i}=$ 0.5 represents the idea that two near neighbors would initially forgo half their autarkic resources to form a single (completely) unified economy, as do the constituent regions of the United States.

For all simulations described in this article, we ran the model for a century, stopping after 100 periods or when all states had been reduced to subsistence, whichever came first. ${ }^{16}$ Because pairs of states are drawn randomly in each period, we replicate each run 500 times to ensure that our results are stable.

14. We are grateful to an anonymous referee for steering us to these authors.

15. This number is of course sensitive to the exact definition of democracy. We used all country-year observations for which there were no missing data and subtracted the autocracy measure from the democracy measure. This yields 13,911 observations on an index ranging from -10 to 10. Following Russett (1993), we treat the 9,958 country-year observations in the bottom two-thirds of this range as nondemocratic. We deliberately use a generous definition of democracy to avoid undercounting the number of strong states, some of whom may be only semidemocratic.

16. If a state has a subsistence level of resources, it cannot attack another. We chose to stop after all states reached subsistence because we did not want to bias our results in favor of the hypothesis that trade occurs simply because every state has lost a war. 


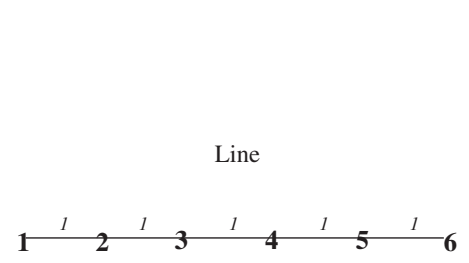

Circle
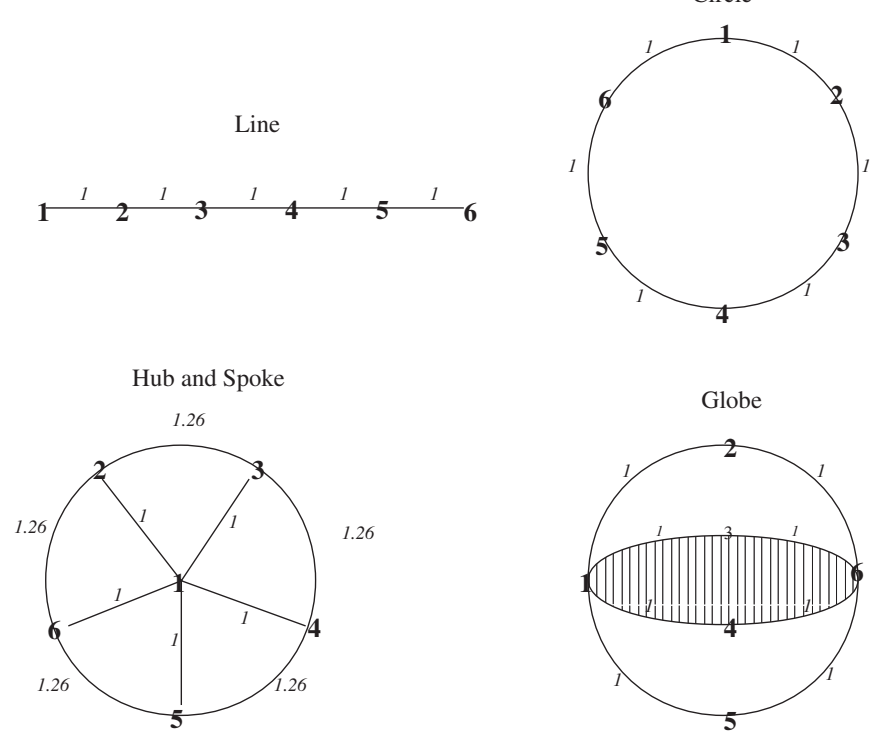

Bimodal

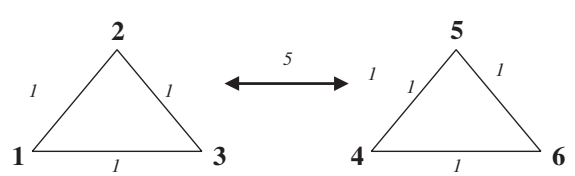

Figure 1: Initial Economic Geographies

NOTE: Bold numbers indicate positions of states; italic numbers indicate initial economic distance between proximate states.

We examine a system of $m=6$ states, with five different initial economic geographies. These are a line, a circle, a hub-and-spoke configuration, a globe, and a bimodal configuration. Other initial geographies could be specified, but these represent perhaps the most interesting geometries in two or three dimensions. ${ }^{17}$ Figure 1 is a pictorial representation of initial geographic configurations. The distances have all been normalized so that the closest state is only one unit away. The hub-and-spoke configu-

17. We also believe that these geographies offer a rough approximation of various regions of the world. The line resembles the distended geography in South and Central America. The circle represents the distended geography in Africa and continental Asia. The hub and spoke has similarities to certain colonial and postcolonial geographies with the metropole as the hub state; it may also resemble the effective geography of the "yen bloc" (Frankel 1993) with Japan as the hub state and other East Asian and Pacific states on the periphery. The compact economic geography in Western Europe looks more like the globe configuration. Finally, the bimodal configuration resembles the cold war situation in which the geography was relatively compact within a bloc but extremely distended between the two blocs. 
TABLE 2

Summary Statistics

\begin{tabular}{lcccc}
\hline \hline $\begin{array}{l}\text { Initial } \\
\text { Geography }\end{array}$ & $\begin{array}{c}\text { Wars per } \\
\text { Replication }\end{array}$ & $\begin{array}{c}\text { Replications Ending } \\
\text { before 100 Periods (\%) }\end{array}$ & $\begin{array}{c}\text { Trade Links per } \\
\text { Replication }\end{array}$ & $\begin{array}{c}\text { Average Correlation } \\
\text { between Trade and War }\end{array}$ \\
\hline Line & 4.99 & 20.00 & 1,496 & .29 \\
Circle & 5.88 & 58.00 & 1,485 & .07 \\
Hub and spoke & 6.01 & 69.00 & 1,680 & -.08 \\
Globe & 6.04 & 67.00 & 1,704 & -.08 \\
Bimodal & 2.91 & 0.40 & 1,357 & .53 \\
\hline
\end{tabular}

ration shows that the (arc) distance between two neighbors on the periphery $2 \pi / 5 \approx$ 1.26 is greater than the distance from any peripheral state to the hub.

\section{THE EFFECT OF INITIAL ECONOMIC GEOGRAPHY}

Table 2 reports summary statistics based for the base cases, including two different measures of conflict. The first is the average number of wars occurring per replication; it tends not to be greater than six because we halt a run when all six states have lost a war and reached subsistence. The second is the percentage of replications ending before 100 periods, when all states have been reduced to a subsistence level. Both measures tell a similar story: the compact configurations (hub-and-spoke and globe) are more bellicose than the distended ones, suggesting that economic proximity makes military conquest and resource extraction easier to achieve.

The average number of trade links per replication measures economic activity within the system. In a replication lasting 100 periods with six states, there can be a maximum of 3,600 trade links if every state traded with every other (including itself) in each period. Likewise, the minimal number of trade links is 600 . The results show, not surprisingly, that economic distance functions as a barrier to trade. The distended geographies show fewer trade links than the compact ones.

After each replication, we also computed the dyadic correlation between war and trade. ${ }^{18}$ The last column in Table 2 shows the average correlation over 500 replications. It is important to note that the correlation between war and trade tends to become more negative as the initial economic geography becomes more compact. The hub-and-

18. During each replication, we keep track of the bilateral patterns of attacks and trade links $6 \times 6$ in matrices whose canonical element indicates the number of times that state $i$ attacks or trades with state $j$. Statistical analyses of trade and war usually do not distinguish between attacking and defending states. So, we add $j$ 's attacks on $i$ to $i$ 's attacks on $j$, yielding 15 dyadic observations of war, after dropping the meaningless observations on the main diagonal because state $i$ never attacks itself. Because trade patterns are automatically symmetric, we also have 15 meaningful dyadic observations of trade links. We then compute the correlation between trade and war after each replication. These 500 observations are independent by construction, because each replication is random. We then compute the average correlation coefficient and check whether it is statistically different from zero using the null hypothesis that the correlations are drawn from a uniform distribution on $[-1,1]$. Under this null hypothesis, the sample mean of these statistics is distributed $N(0,1 / \sqrt{3 n})$, where $n$ is the sample size. Thus, all these sample means are highly significant. 


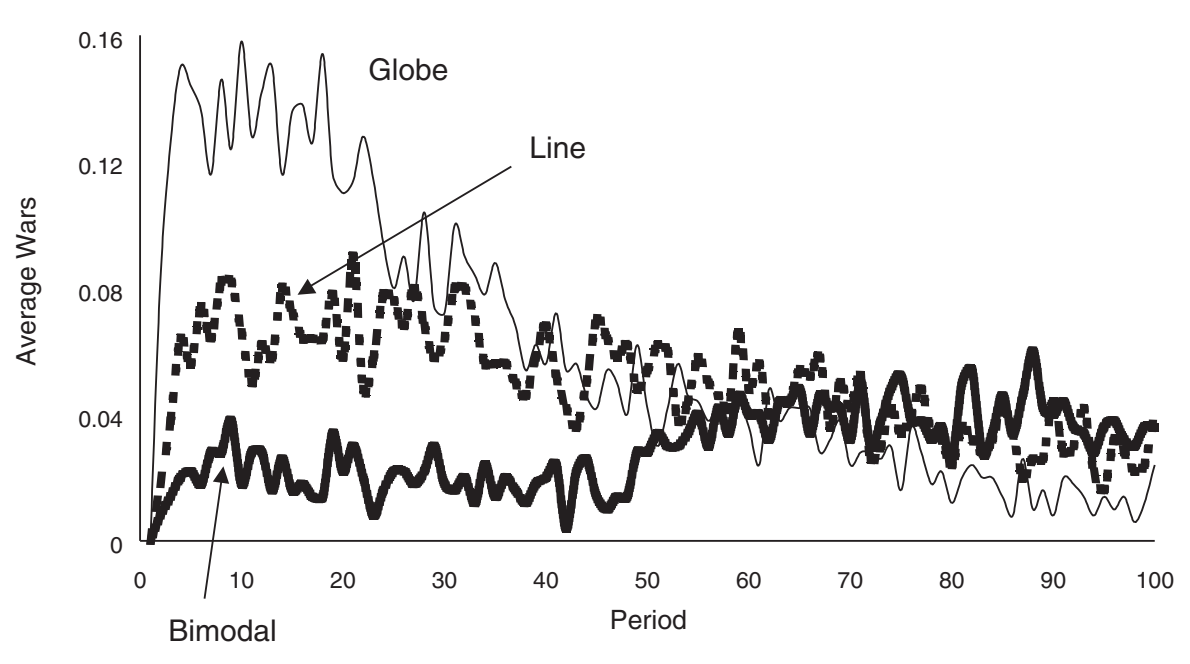

Figure 2: Timing of Conflict

spoke and globe configurations exhibit a negative correlation, whereas the more distended line and circle show a positive correlation. The correlation between war and trade in the bimodal geography is highly positive.

The dyadic correlation between trade and war will be a recurring theme of our empirical analysis. Thus, it is worth emphasizing the three constituents of this correlation in the model. First, there is a negative short-run correlation between trade and war, simply because the dyad severs a trade link when it goes to war. Second, this correlation is inherently biased toward one in the distended configurations because distant states can neither trade nor go to war. Third, the model makes it clear that one needs to control for the current configuration of trading partners if one wants to reconstruct the predicted negative (partial) correlation between trade and war. For simplicity and to make our results widely comparable with the current empirical literature, we report only the long-run (total) correlation that a statistician would observe in a panel consisting of a century of dyadic data. Finally, we must emphasize that each particular history is random. Thus, it is entirely possible for one particular run to get a positive correlation between trade and war in the globe configuration, even though the average of these numbers over 500 runs is statistically significantly negative.

These summary statistics obscure important differences with regards to the timing of conflict and the patterns of trade and war within different initial economic geographies. Figure 2 shows the average number of wars in each period for three configurations. Wars occur at a relatively uniform rate in the somewhat peaceful line configuration. This contrasts with the timing of conflict in the globe, where the early periods are marked by heavy conflict, which then tapers off in later periods. The bimodal configuration exhibits little conflict in early periods, and wars tend to occur more frequently in later ones. 


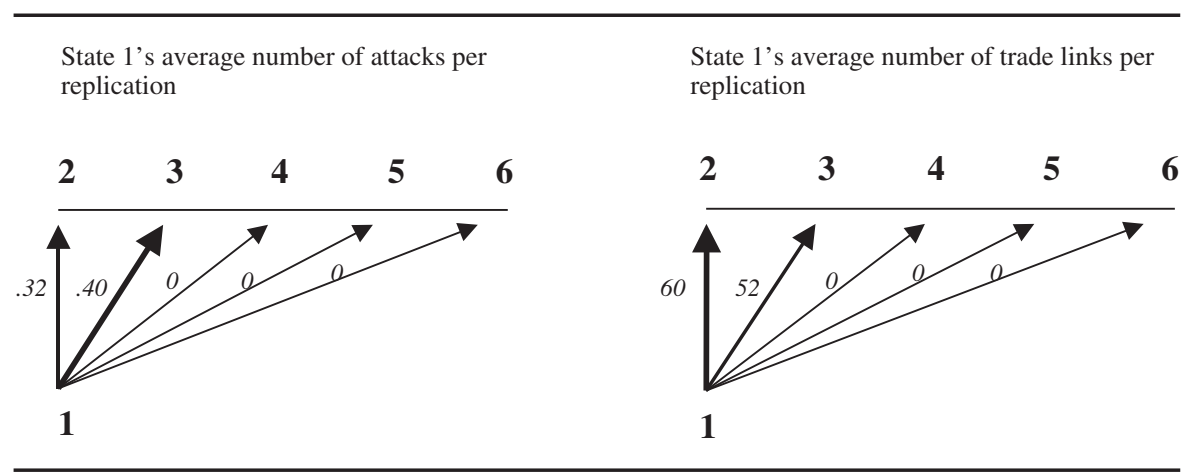

Figure 3: Patterns of War and Trade in the Line

This chronology of conflict occurs in part for the following reasons. In the globe, states quickly establish different trading networks, and military conflict with states not having the same set of trading partners becomes immediately attractive. This conflict tails off as aggressors inevitably lose wars and revert to a subsistence level. In the bimodal configuration, symmetric trading networks quickly emerge within each bloc, so conflict is less attractive in early periods due to the implicit balance of power. However, when a unilateral demand for additional resources does occur, trading relationships are cut, creating asymmetric trade patterns and a local imbalance of power. These factors make conflict more attractive, and wars become more frequent in later periods.

Initial economic geography also relates directly to the dyadic patterns of war and trade within the system. In the distended line configuration, trade and war fall with initial economic distance. Indeed, an initial economic distance greater than three acts as an effective barrier to any economic exchange or military conquest. For example, neither state at the ends of the line can reach the three most distant states in the system. State 1's patterns of attack and trade shown in Figure 3 illustrate this fact.

If a state near the end of the line desires goods produced by states near the other end, then it must attack the central states, called state 3 and state 4 . Only these states are able to trade with those at the opposite end. Hence, they become the most frequent targets of attack in this initial geography, being the recipient of 57\% of total attacks (versus 33\% if the attacks were evenly distributed across the six states). Despite these attacks, which sever the relevant bilateral trade link, the central states still take part in 39\% of all trade links in the system. The correlation between war and trade is positive because states at one end of the line cannot attack or trade with states at the other end.

In the circle, each state faces the same initial geography as a central state in the line. Thus, given the baseline parameters, a state can potentially reach all other states in the system except its opposite. If a state desires the distant good, then it must attack another state trading with its opposite number. In fact, all other states can potentially trade with their opposite, so the attack pattern becomes relatively uniform across reachable states. State 2's pattern of attacks in Figure 4 illustrates this relationship. 


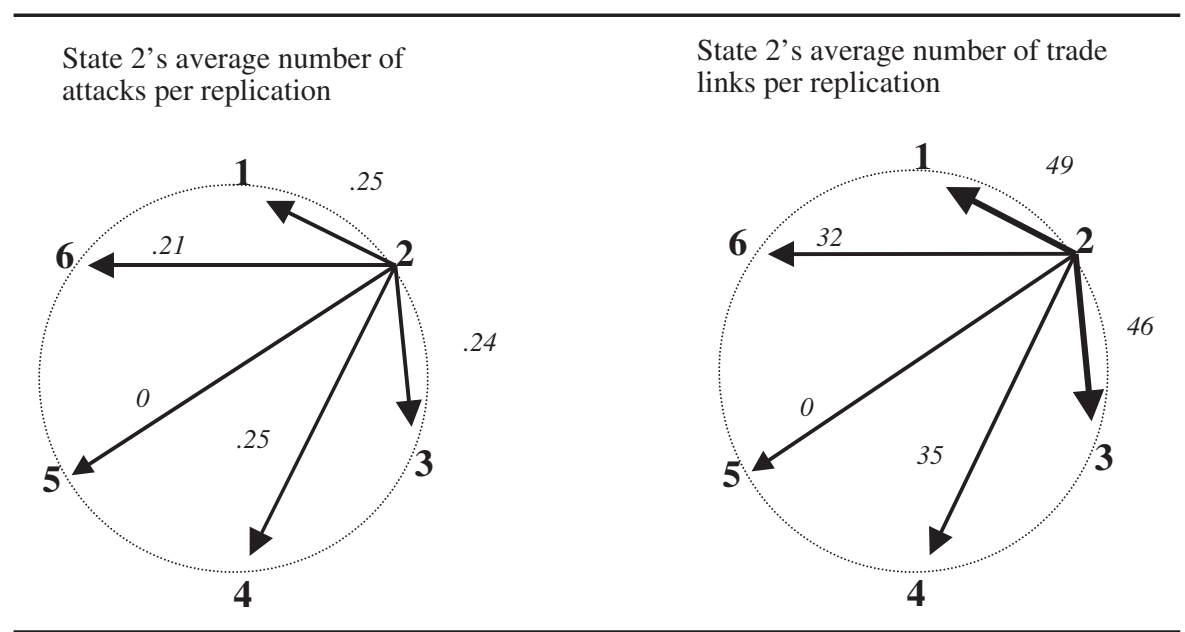

Figure 4: Patterns of War and Trade in the Circle

State 2's average number of attacks per replication

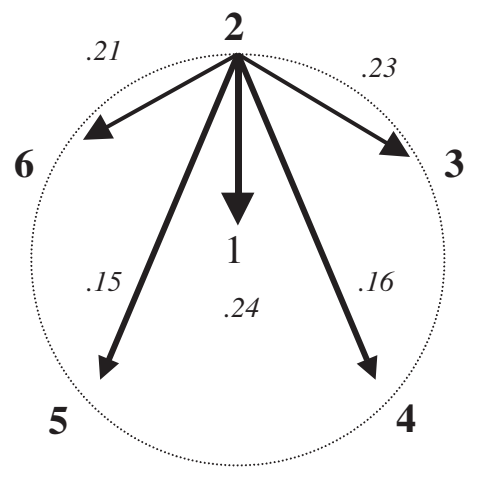

State 2's average number of trade links per replication

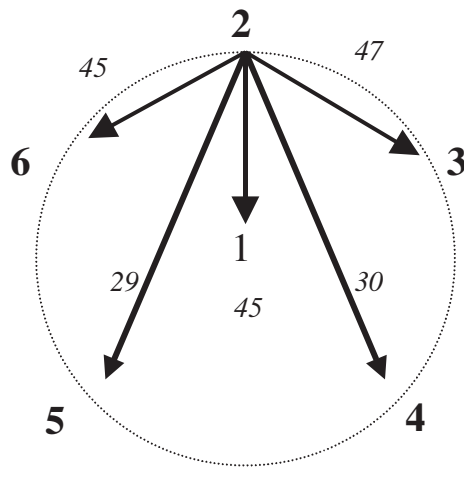

Figure 5: Patterns of War and Trade in the Hub and Spoke

In the more compact hub-and-spoke configuration, each state can potentially reach every other. But the configuration is asymmetric because the hub enjoys a maximally compact initial geography. On the periphery, trade falls with distance. Figure 5 uses state 2 (a peripheral state) as an example again. That state tends to trade as much and sometimes more with its peripheral neighbors as it does with the hub. This fact occurs because state 1 (the hub) represents a potentially lucrative target for military conquest because its central position allows it to trade easily with all other states, giving it a rich array of goods for usurpation. Indeed, the hub suffers more than $1 / 6$ of the attacks in the 


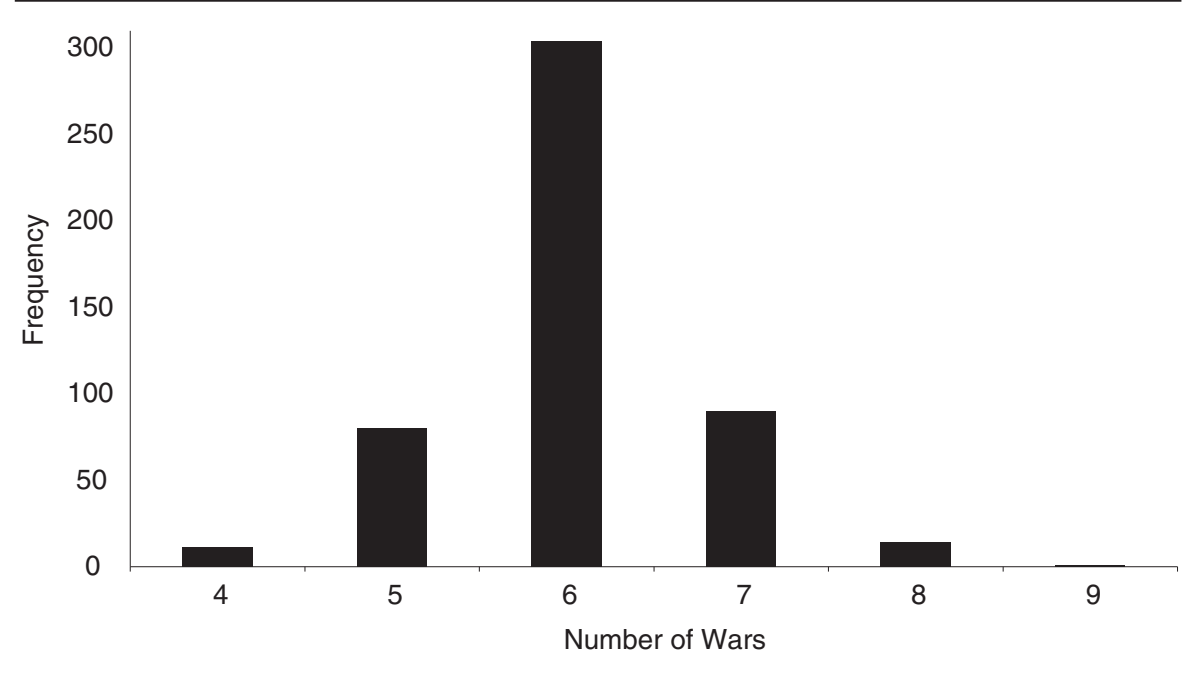

Figure 6: Histogram of Wars in Globe

system. Due to these frequent attacks, trade with the hub state gets somewhat depressed.

In the compact globe configuration, trade and war both fall with distance. A state trades and fights less with its global antipode than with its four closer neighbors. Although this configuration exhibits the highest average number of trade links per replication, the globe - not unlike the hub-and-spoke-is usually quite violent. Figure 6 shows that the globe system never exhibits fewer than four wars and sometimes seven or more. Such a bellicose run can occur when a strong state repeatedly attacks and beats a weaker one.

In contrast, the bimodal configuration is relatively peaceful, as shown in Figure 7. Given the high initial economic distance between the two blocs, states are able to trade and fight only within their own bloc. Hence, the correlation between trade and war becomes strongly positive. The easiest way to explain this correlation is to think of a world on the eve of the modern era that consists of England, France, and Germany and Korea, Japan, and China. Because the two blocs are so far apart in economic distance, there will never be any trade or conflict between members of two different groups; all such activity must be local. Indeed, there is much economic activity within each bloc; each state has a trade link with its two close neighbors in $63 \%$ of the periods.

\section{THE EFFECT OF REVISIONISM}

Holding all the other baseline parameters constant at their values in Table 1, we varied the states' levels of revisionism $\rho \equiv \rho_{i}, i=1, \ldots, 6$. Revisionism is a unit-level parameter, but consistent with the spirit of strong symmetry in this model, we first 


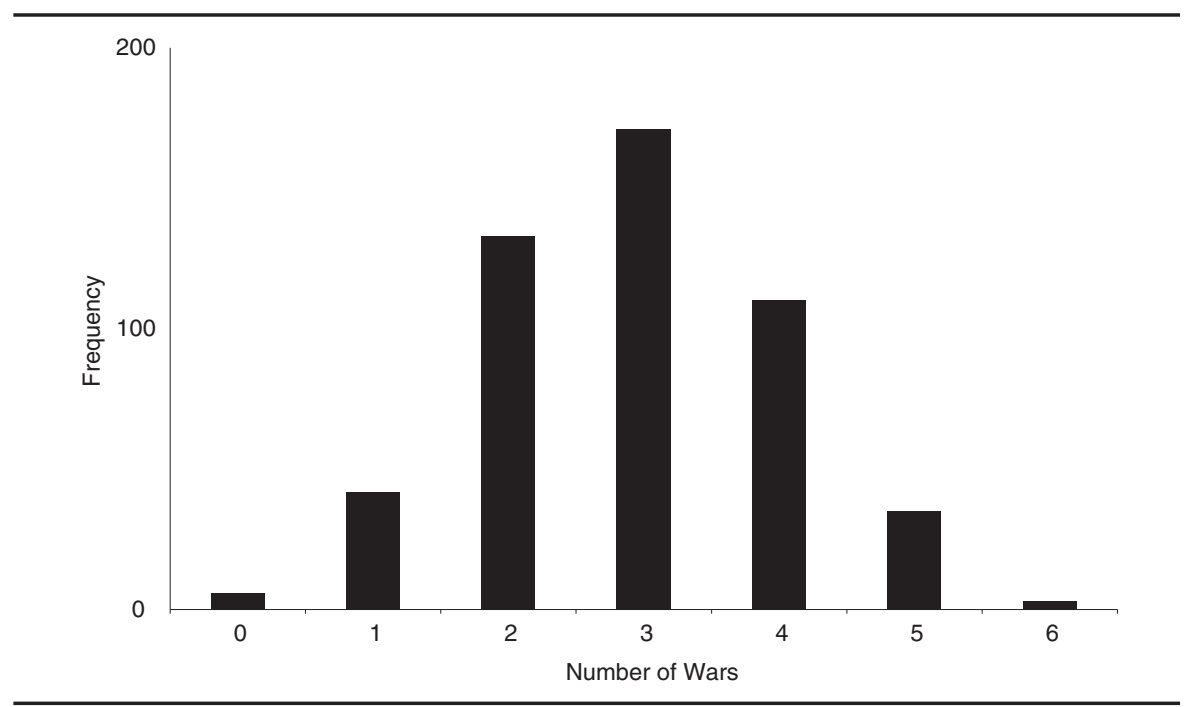

Figure 7: Histogram of Wars in Bimodal

adjust it for all the states in the system. We initially concentrate on the effects of revisionism in the globe, which is the most compact initial configuration.

Table 3 reports the average number of wars and trade links per replication for each symmetric value of the revisionism parameter. It shows that a state's desire to obtain the goods of others motivates both war and trade. When all states have a high level of revisionism, there is a very strong incentive to trade, and states with equally diverse resource bases are equally powerful. This balance of power acts as a partial deterrent to war in the initial stages of the development of the global trading network. The economic geography evolves so that the states become closer together, and there is typically a negative correlation between trade and war.

However, when $.4 \leq \rho \leq .5$, this usually negative correlation is actually reversed. As global revisionism declines, the world becomes more fragmented. Often a state will not have the incentive to trade with its antipode. A fragmented trading network tends to make the correlation between trade and war positive, because a state will neither trade nor go to war with another that is too distant. Eventually, wars dissipate completely when states have a revisionism parameter of $\rho \geq .6$. States become content with their own good, and they neither threaten nor attack their neighbors. Likewise, the world economic geography never evolves; in essence, the system remains a completely fragmented network of autarkic states.

Revisionism obviously has important effects on the patterns of war and trade. In a global system of highly revisionist actors, a state takes advantage of initial geographic proximity to attack its near neighbors at almost twice the rate as its antipode. This local conflict disrupts trade patterns with the close neighbors enough so that it actually engages in more economic exchange with its antipode, despite the pair's greater initial 
TABLE 3

Revisionism

\begin{tabular}{|c|c|c|c|c|c|}
\hline \multicolumn{3}{|c|}{ Symmetric Revisionism } & \multicolumn{3}{|c|}{ Asymmetric Revisionism } \\
\hline$\rho$ & Wars & Trade Links & $\rho_{1}$ & Wars & Trade Links \\
\hline .1 & 6.76 & 1,614 & .1 & 13.80 & 2,283 \\
\hline .2 & 6.07 & 1,637 & .2 & 6.32 & 2,003 \\
\hline .3 & 5.94 & 1,753 & .3 & 6.00 & 1,685 \\
\hline .4 & 5.94 & 1,641 & .4 & 6.03 & 1,737 \\
\hline .5 & 5.77 & 1,277 & .5 & 5.54 & 1,874 \\
\hline .6 & 0 & 600 & 6 & 5.26 & 1,781 \\
\hline .7 & 0 & 600 & .7 & 5.20 & 1,787 \\
\hline .8 & 0 & 600 & .8 & 5.19 & 1,787 \\
\hline .9 & 0 & 600 & .9 & 5.25 & 1,761 \\
\hline
\end{tabular}

economic distance. In a global system with less revisionist actors, a state finds the initial distance to its antipode too great to justify military conquest. So it never threatens or attacks its antipode, although it has occasional conflict with its closer neighbors. It also ceases to trade with its antipode, but it exchanges voluntarily with closer states. Thus, at high revisionism, transglobal trade is a frequent occurrence, but economic exchange becomes more local with lower revisionism.

We now examine the effect of asymmetric changes in revisionism. Again using the globe configuration, we vary $\rho_{1}$, leaving $\rho \equiv \rho_{i}=1 / 3, i=2, \ldots, 6$, and all other baseline parameters unchanged. The right half of Table 3 shows that a system with one highly revisionist actor $\left(\rho_{1}=.1\right)$ is quite bellicose. The revisionist state becomes more powerful if it has at least one trading partner and is thus able to prevail in most military contests against third parties. Indeed, it often reduces the other states to a subsistence existence and then continues to attack the weaker states until it finally loses a military contest by chance. Asymmetric changes in revisionism can have an ambiguous effect on global trade. Trade exhibits a local modest peak when $\rho_{1}=.5$. At this value, the moderately revisionist state 1 is still sufficiently motivated to engage in economic exchange, but it is rarely worthwhile to attack other states; thus, fewer trade links are cut.

Figure 8 maps the pattern of war and trade in the globe with one highly revisionist state in the international system. State 1 attacks all other states more than two times in the average replication, accounting for $80 \%$ of the conflict in the globe system. The revisionist state's increased power also means that it is almost never a target of aggression. State 1 trades with each of the other states in roughly half of the periods in an average replication. These other, less revisionist states trade among themselves more frequently. Thus, economic activity is robust among the more peaceful dyads and curtailed in dyads involving the aggressive revisionist actor. Indeed, the correlation between bilateral trade and war is very strongly negative in this case. 
State 1's average number of attacks per replication

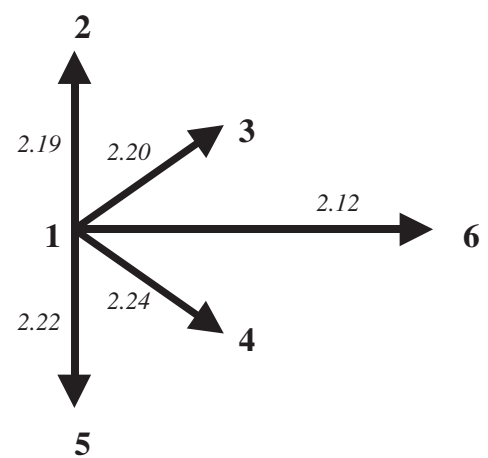

State 1's average number of trade links per replication

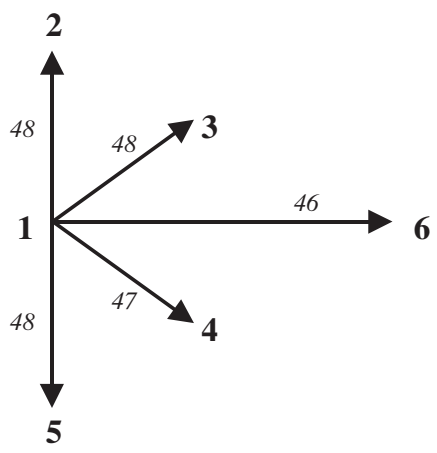

Figure 8: Patterns of War and Trade in the Globe with Asymmetric Revisionism $\left(\rho_{1}=.1\right)$

When $\rho_{1}=.9$, the first state ceases all trade, and the other states now attack the weaker state 1 . It receives $28 \%$ of the attacks versus roughly $17 \%$ if all attacks were evenly distributed. Indeed, this state becomes isolated in the trading network, and the global correlation between trade and war tends to become slightly more positive. This phenomenon explains why there is not a substantial diminution in global conflict when just one state becomes less revisionist.

We also studied the effect of revisionism in the hub-and-spoke configuration. Changes in systemwide revisionism are similar to those in the globe. The frequency of war declines with revisionism, and trade again reaches a peak when $\rho=.3$. Again, the correlation between trade and war may even become positive when systemwide revisionism is lower. In that case, the hub-and-spoke becomes more fragmented, and the pattern of attacks changes. As revisionism declines, the hub actually becomes the victim of an increasing share of attacks. The hub is a lucrative target for a peripheral state that cannot trade with other distant states, and modest levels of revisionism mean that the hub is not much stronger than a peripheral state with one similar trading partner.

Asymmetric changes in revisionism in this configuration are perhaps the most interesting case of all. We analyzed the natural case, where the hub's degree of revisionism varies, while holding all the other parameters-including the revisionism of all the peripheral states-at the baseline values. When the hub is highly revisionist, there is a lot of war and trade. The hub quickly becomes so strong that it is never attacked, and it attacks a peripheral state almost any chance it has. Still, there is a lot of trade, because the weak peripheral states trade among themselves. There are very few wars among the peripheral states because they are often reduced quickly to subsistence by the powerful hub. 
The exact opposite happens when the hub has a low degree of revisionism. In particular, when $\rho_{1}=.9$, state 1 remains a weak and isolated state, a hub only in name. State 1 is attacked very frequently, and the initial hub-and-spoke configuration actually becomes almost like the circle with an isolated weak island. Hence, the trade patterns among the peripheral states are similar to that in a circle with only five states, and the correlation between trade and war is negative largely because every state attacks the weak hub, and no one bothers to trade with it. Thus, the correlation between trade and war is negative partly because every state attacks the weak and autarkic central state!

\section{THE EFFECT OF THE DEFENSIVE ADVANTAGE IN WAR}

We performed sensitivity analysis on the defensive advantage in war. Using the globe, where conflict tends to be high, we adjusted both defense parameters by the same multiple, setting the average defensive advantage at integer values from 1 to 9 . Greater defensive advantage has the expected effect of reducing conflict in the system. A growing defensive advantage in war also serves to increase economic activity among states in the globe system.

This aspect of the model raises an interesting possibility underlying the broad expansion of international trade in the latter half of the 20th century. This period saw the proliferation of nuclear weapons, considered by many to be the ultimate in defensive war technologies. Thus, the rise in economic activity among states with nuclear weapons or under the shadow of a nuclear umbrella may be due largely to the relative lack of appeal of offensive military options in the nuclear age. ${ }^{19}$ Hence, actions that undermine nuclear deterrence (a ballistic missile defense) or demonstrate the potential utility of nuclear weapons in offense (the use of tactical nuclear weapons) may depress international economic activity.

Again using the globe, we also did sensitivity analysis on the variance of defense types. Assuming that the average defensive advantage in war is 3 , we reduced the difference between strong and weak types gradually from 7.14 in the base case to 0 . When there is no difference between strong and weak types, the defender is known with certainty. The simulation results show that decreased uncertainty about the defender's strength leads to fewer wars but more nickel-and dime demands for resources. Because these threats sever the relevant bilateral trade links, more certainty about the defender's strength is also associated with less trading activity. Still, this relationship is not monotonic. Intermediate values for this difference actually give rise to the greatest number of trading links. This result emerges because there is still some uncertainty about the defender's type, and voluntary exchange is often more worthwhile than small nickel-and-dime demands.

19. We thank an anonymous reviewer for pointing out that this logic does not explain why there was an expansion of trade among the Western states but not a concurrent East-West trade boom during the cold war Our response is that the economic geography between the Western and Eastern blocs was distended, like our bimodal configuration. The Iron Curtain is a good example of how economic and physical geography can be quite different. Indeed, there was a "trade" boom within the Eastern bloc during this time, especially because an important Soviet war goal had been the destruction of the manufacturing infrastructure of Eastern Europe. 
THE EFFECT OF EXOGENOUS TECHNOLOGICAL

PROGRESS MAKING TRADE EASIER

In these final simulations, we examine the effect of technological change on the economic geographic infrastructure. It is perhaps appropriate to think of this kind of technological progress as exogenous "globalization." In choosing the baseline parameters, we allowed for a pair of states to become $4 \%$ closer in each period $(\delta=.04)$ only if there was an extant trade link between them. Now we allow them to become closer both through learning by trading and through exogenous technological progress affecting the economic geographic infrastructure. In equation (2), $\delta$ and $\theta$ work in tandem to reduce the economic distance between states. Because the parameter $\theta$ reduces this distance even if the pair of states does not engage in trade, two states unable to interact in early periods may become sufficiently close to engage in war or trade in later periods.

We want to remain consistent with the historical evidence from Maddison (1982), so we consider five combinations such that $\delta+\theta=.04$ and hold all other baseline parameters constant. We let $\theta \in\{0, .01, .02, .03, .04\}$. The first case is the original baseline; states can become closer only through trade. The fifth posits that all states become $4 \%$ closer in each period, whether or not they engage in trade. The bimodal initial economic geography represents an interesting choice for this analysis because it contains two distinct blocs unable to interact unless exogenous technological progress shortens the initial geography between distant states.

Technological advances shortening the economic distance between all states not only leads to increased trade but also facilitates war as the two blocs become sufficiently close to engage in economic exchange and military conquest. The frequency of wars doubles, but trade links only rise by about $25 \%$. Exogenous technological change also has important effects on the timing of conflict in the international system. When $\theta=.01$, the bimodal geography shows little conflict in early periods, then a steady increase in conflict beginning about the 50th period as the blocs become close enough to make military conquest across the system a potentially profitable endeavor. When $\theta=.04$, the rise in conflict occurs much earlier. Recall that with no exogenous technological change, this configuration was fairly peaceful. But with high technological change, $65 \%$ of the replications in this initial geography now end with all states at the subsistence level.

In short, globalization makes the initial geography of the international system less important. This kind of change allows different initial geographies to evolve toward a common configuration where all states effectively occupy the same point in space and

there is no economic distance between any pair. This compactness can produce trade; it can also facilitate military conquest.

\section{CONCLUSION}

We began this article by asking, What is the relationship between international trade and war? To explore this question, we developed an agent-based computer model 
in which economic exchange and military conflict were emergent processes within a system of states motivated to increase their resources and power. Our simulation results show that the relationship between trade and war is highly conditioned on third factors, such as unit-level revisionism and the initial economic geography of the system. An inverse relationship between trade and war emerges from compact economic geographies with highly revisionist states.

Most of the statistical work on trade and war has utilized a limited sample of cases ${ }^{20}$ often focusing on "politically relevant dyads," defined as pairs of contiguous states or pairs of states including a major power. With some exceptions, these studies tend to show an inverse relationship between dyadic trade and war, consistent with the liberal hypothesis. Our results do not contradict these findings, but they do suggest the need to think further about sample selection and control variables.

Lemke and Reed (2001) recently showed that although the focus on politically relevant dyads may introduce some selection bias, it does not substantively affect the statistical estimates. Nonetheless, enlarging the sample to include all dyads with available data, thus including more distended state pairs, does weaken the estimated inverse relationship between trade and war as Oneal and Russett $(1999,431)$ show. These scholars also demonstrate that a strong inverse relationship reemerges after controlling for both the distance between a pair of states and their contiguity (ibid., 433). ${ }^{21}$

The statistical effect of their distance variable further demonstrates the importance of economic geography. We note, however, that economic geography includes not only the physical distance between two states but also the technology and economic infrastructure linking them. Thus, although further apart in distance, the United States and the United Kingdom may be "closer" than Chile and Argentina, for example. Likewise, although geographically proximate, the two Germanys were economically "distant" during the cold war as the roads and railways connecting the two states were blocked and even dismantled.

In future studies, we urge scholars to broaden their sample to include noncontiguous states that are part of the same trading networks. Of course, geographically separated states engage in trade, and many economic blocs include states without common borders. ${ }^{22}$ Furthermore, distant states do engage in some military conflict and even major war. ${ }^{23}$ We also encourage scholars to take greater account of the evolving economic geography between states, including technological innovations that make trade

20. See Barbieri and Schneider $(1999,395)$ for a concise summary of the statistical work on trade and war.

21. See also the reprinted table in the Journal of Peace Research 36 (1999): 626. It is important to consider what a contiguity term really measures when a distance variable is added to the equation. Lemke and Reed $(2001,141)$ argued that a control variable for "contiguity within a relevant dyad data set might inadvertently be a control for joint-minor-power status." If such minor power pairs compete with each other for regional primacy and power, then a contiguity term may be picking up on the more revisionist tendencies within these dyads, especially when looking at all dyads and controlling for distance.

22. There are numerous such examples: Austria and Ireland in the European Union, Côte d'Ivoire and Nigeria in the Economic Community of West African States, and Brazil and Chile (associate member) in the Southern Cone Common Market.

23. Lemke and Reed (2001) identified 301 militarized interstate disputes among politically "irrelevant" dyads, including 34 such disputes coded as wars. 
or war easier. Scholars should also model the differing revisionist tendencies of states in the international system. Revisionism, which motivates both economic exchange and military conquest, is not directly measured in any recent analysis of international trade and war.

\section{REFERENCES}

Backus, David K., Patrick J. Kehoe, and Finn E. Kydland. 1994. Dynamics of the trade balance and the terms of trade: The J-curve? American Economic Review 84:84-103.

Barbieri, Katherine, and Gerald Schneider. 1999. Globalization and peace: Assessing new directions in the study of trade and conflict. Journal of Peace Research 36:387-404.

Bremer, Stuart A., and Michael Mihalka. 1977. Machiavelli in machina: Or politics among hexagons. In Problems of world modeling, edited by Karl W. Deutsch, Bruno Fritsch, Helio Jaguaribe, and Andrei S. Markovits. Cambridge, MA: Ballinger.

Bueno de Mesquita, Bruce, James D. Morrow, Randolph M. Siverson, and Alastair Smith. 1999. An institutional explanation of the democratic peace. American Political Science Review 93:791-807.

Buzan, Barry. 1984. Economic structure and international security: The limits of the liberal case. International Organization 38:597-624.

Carr, Edward Hallett. 1946. The twenty years' crisis, 1919-1939: An introduction to the study of international relations. New York: Harper and Row.

Cederman, Lars-Erik. 1994. Emergent polarity: Analyzing state-formation and power politics. International Studies Quarterly 38:501-33.

Cusack, Thomas R., and Richard Stoll. 1990. Exploring realpolitik: Probing international relations theory with computer simulations. Boulder, CO: Lynne Rienner.

Doyle, Michael W. 1986. Liberalism and world politics. American Political Science Review 80:1151-69.

Epstein, Joshua M., and Robert Axtell. 1996. Growing artificial societies: Social science from the bottom up. Washington, DC: Brookings Institution.

Fearon, James D. 1995. Rationalist explanations for war. International Organization 49:379-414.

Frankel, Jeffrey A. 1993. Is Japan creating a yen bloc in East Asia and the Pacific? In Regionalism and rivalry: Japan and the United States in Pacific Asia, edited by Jeffrey A. Frankel and Miles Kahler. Chicago: University of Chicago Press.

Fujita, Masahisa, Paul Krugman, and Anthony J. Venables. 1999. The spatial economy. Cambridge, MA MIT Press.

Gartzke, Erik. 1999. War is in the error term. International Organization 53:567-87.

Gleditsch, Kristian S., and Michael D. Ward. 2000. War and peace in space and time: The role of democratization. International Studies Quarterly 44:1-29.

Grieco, Joseph M. 1988. Anarchy and the limits of cooperation: A realist critique of the newest liberal institutionalism. International Organization 42:485-507.

. 1990. Cooperation among nations: Europe, America, and non-tariff barriers. Ithaca, NY: Cornell University Press.

Hirshleifer, Jack. 1995. Anarchy and its breakdown. Journal of Political Economy 103:26-52.

Hoffman, Stanley. 1963. Rousseau on war and peace. American Political Science Review 57:317-33.

Jaggers, Keith, and Ted Robert Gurr. 1995. Tracking democracy's third wave with the Polity III data. Journal of Peace Research 32:469-82.

Jodhimani, Albert G. 1999. Transactions costs and the evolution of market completeness. Ph.D. diss., The Ohio State University, Columbus.

Judd, Kenneth L. 1998. Numerical methods in economics. Cambridge, MA: MIT Press.

Kissinger, Henry A. 1957. A world restored: Castlereagh, Metternich, and the problem of peace, 1812-22. Boston: Houghton Mifflin.

Lake, David A. 1992. Powerful pacifists: Democratic states and war. American Political Science Review 86:24-37. 
Lemke, Douglas, and William Reed. 2001. The relevance of politically relevant dyads. Journal of Conflict Resolution 45:126-45.

Liberman, Peter. 1996. Does conquest pay? The exploitation of occupied industrial societies. Princeton, NJ: Princeton University Press.

Maddison, Angus. 1982. Phases of capitalist development. Oxford: Oxford University Press.

Mansfield, Edward D., and Brian M. Pollins. 2001. The study of interdependence and conflict: Recent advances, open questions and directions for further research. Journal of Conflict Resolution 45:834-59.

Mastanduno, Michael. 1991. Do relative gains matter? America's response to Japanese industrial policy. International Security 16:73-113.

McMillan, Susan M. 1997. Interdependence and conflict. Mershon International Studies Review 41:33-58.

Mearsheimer, John J. 1989. Assessing the conventional balance: The 3:1 rule and its critics. International Security 13:54-89.

Morgenthau, Hans J. 1948. Politics among nations: The struggle for power and peace. New York: Knopf.

Morrow, James D. 1989. Capabilities, uncertainty, and resolve: A limited information model of crisis bargaining. American Journal of Political Science 33:941-72.

Oneal, John R., Frances H. Oneal, Zeev Maoz, and Bruce M. Russett. 1996. The liberal peace: Interdependence, democracy, and international conflict, 1950-85. Journal of Peace Research 33:11-28.

Oneal, John R., and Bruce M. Russett. 1997. The classical liberals were right: Democracy, interdependence, and conflict, 1950-85. International Studies Quarterly 41:267-94.

1999. Assessing the liberal peace with alternative specifications: Trade still reduces conflict. Journal of Peace Research 36:423-42.

Reiter, Dan, and Alan Stam III. 1998. Democracy, war initiation, and victory. American Political Science Review 92:377-89.

Rosecrance, Richard. 1986. The rise of the trading state: Commerce and conquest in the modern world. New York: Basic Books.

Russett, Bruce. 1993. Grasping the democratic peace. Princeton, NJ: Princeton University Press.

Schweller, Randall L. 1994. Bandwagoning for profit: Bringing the revisionist state back in. International Security 19:72-107.

Schweller, Randall L., and David Preiss. 1997. A tale of two realisms: Expanding the institutions debate. Mershon International Studies Review 41:1-32.

Tetlock, Philip E., and Aaron Belkin. 1996. Counterfactual thought experiments in world politics. Princeton, NJ: Princeton University Press.

Wallis, John J., and Douglas C. North. 1986. Measuring the transactions sector in the American economy. In Long-term factors in American economic growth, edited by Stanley Engerman and Robert Gallman. Chicago: University of Chicago Press.

Waltz, Kenneth N. 1970. The myth of national interdependence. In The multinational corporation, edited by Charles Kindleberger. Cambridge, MA: MIT Press. 